\title{
Enucleation after Marsupialization: A case report of Globulomaxillary Cyst
}

\author{
*Mojumder $\mathrm{D}^{1}$, Chowdhury $\mathrm{RU}^{2}$, Podder $\mathrm{A}^{3}$
}

\section{AFFILIATION:}

1. Dr. Dipayan Mojumder, BDS, BCS (Health)

Lecturer

Dept. of Dental Public Health

Dhaka Dental College, Dhakam Bangladesh

2. Dr. Rahim Ullah Chowdhury, BDS, DDS, MCPS, MS (OMFS)

Assistant Professor

Oral and Maxillofacial Surgery dept.

Chittagong Medical College Dental Unit, Chittagong, Bangladesh

3. Dr. Anupam Podder, BDS, MS

Associate Professor

Dept. of Oral Pathology and Periodontology

Dhaka Dental College, Dhaka, Bangladesh

\section{Article info.}

Received: 07 November 2019

Accepted: 15 January 2020

Volume: 10, Issue-1 April, 2020

DOI: https://doi.org/10.3329/updcj.v10i1.46689

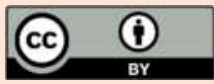

(C) Authors retain copyright and grant the journal right of first publication with the work simultaneously licensed under Creative Commons Attribution License CC - BY 4.0 that allows others to share the work with an acknowledgment of the work's authorship and initial publication in this journal.

https://creativecommons.org/licenses/by/4.0/

Publisher: Update Dental College, Dhaka, Bangladesh

Web: www.updatedentalcollege.edu.bd

E-mail: updcj@hotmail.com
* Corresponding Author

Dr. Dipayan Mojumder, BDS, BCS (Health)

Lecturer, Dept. of Dental Public Health

Dhaka Dental College, Dhakam Bangladesh

Email: dipayan.m.ddc@gmail.com

Cell: +8801748694899

\section{Citation}

Mojumder D, Chowdhury RU, Podder A. Enucleation after Marsupialization: A case report of Globulomaxillary Cyst .UpDCJ.2020 Apr;10(1):25-27

Available from: DOI: https://doi.org/10.3329/updcj.v10i1.46689

\begin{abstract}
Globulomaxillary cyst found in between the roots of lateral incisor and canine of maxilla and is a non-odontogenic developmental origin. It is usually diagnosed by routine radiographic examination and it is inverted peer shaped radiolucent lesion. Adjacent teeth remain vital. Complete enucleation or marsupialization is a treatment option for this. This case report is to observe the expected results after marsupialization followed by enucleation. An eighteen years old boy noticed a painless swelling for 1 year at the left side of upper lip and we performed surgery enucleation after doing marsupialization. Here, marsupialization done to promote bone regeneration and to avoid injury to vital structures and possible fracture. Patient was followed for 3 months after enucleation and the radiolucent area was gradually reduced.This article reports the management of a globulomaxillary cyst in at two-stage procedure and it was more conservative. It might be a good treatment option for management of globulomaxillary cyst.
\end{abstract}

\section{KEYWORDS: Globulomaxillary cyst, Marsupialization, Enucleation, Jaw cysts, Non odontogenic cyst.}

\section{INTRODUCTION}

Globulomaxillary cyst is a rare cyst found between lateral incisor and canine in maxilla. Also it is known as fissural cyst at the junction of maxillary process and medial nasal process. It starts from non- odontogenic epithelium constitutes about $17 \%$ of all non-epithelial and non-odontogenic cysts of maxilla and mandible. ${ }^{(1)}$

It is usually found clinicallyby routine radiographic examination. Sometimes presents as a soft reddish swelling in the labial aspect of maxilla at cuspid region. Swelling may extend also at palatal side. Crown of lateral incisor and canine may diverse and extraorally, obliteration of nasolabial fold is found.Radiographically, it is well-defined radiolucent lesion and most of the time the shape is inverted pear like. ${ }^{(2)}$

The established treatment of the jaw cysts is the enucleation that is excision of cyst with lining or can perform marsupialization before enucleation. Marsupialization is a procedure of creating a bony window in overlying mucoperiosteum and suturing the mucosal boarder with cystic wallwhich allows decreasing intra-cystic pressure and increasing bone growth before enucleation. Marsupialization is done when the cyst is large enough and enucleation might cause damage to adjacent tooth root and vital structures such as mental nerve, inferior alveolar nerve, maxillary sinus etc. It has also having the risk of pathological fractures. ${ }^{(3)}$

This article reports the treatment of a globulomaxillary cyst by marsupialization followed by enucleation as it is a large cyst and to preserve the dentition, avoid penetration into nose and prevent the injury to the nerves supplying the area. 


\section{CASE REPORT:}

A male patient of 18 years reported to a maxillofacial clinic with the complaint of left side of upper lip swelling for 1 year and it was painless. Swelling was initially small in size, but gradually enlarged into present condition. Patient has no history of trauma, missing teeth or infection. Associated symptoms were mobility of the left sided upper lateral incisor and canine and slight bleeding in the gingival margin of lateral incisor for last 7 days.

Extraorally found an ill-defined spherical swelling anteroposteriorly extending from philtrum to left corner of mouth and from left ala of the nose to vermillion border of upper lip superoinferiorly. Left nasolabial fold was obliterated and skin condition was normal.On palpation, we found local temperature was normal and swelling was non-tender, bony hard in consistency. (Fig: 1)
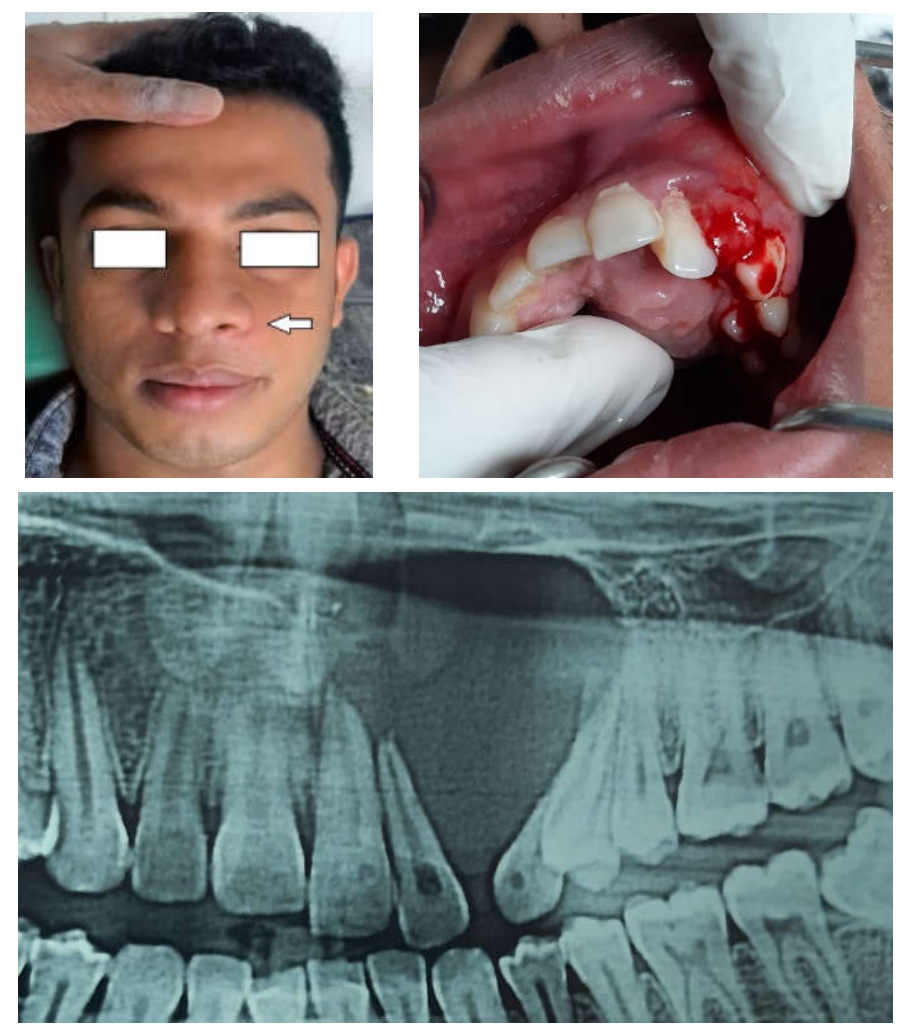

Figure 1: Extraoral picture of patient. Arrow shows obliteration of nasolabial fold, Figure 2: Intraoral picture of lesion, Figure 3: Initial OPG showing inverted peer shaped lesion. (From upper left to right and below)

On intraoral examination there was a well-defined, rounded swelling about $3 \mathrm{~cm} \times 3 \mathrm{~cm}$ in size. Buccally, the swelling obliterates the vestibule from distal of the upper left central incisor to the mesial of first premolar and palatally extending $2.5 \mathrm{~cm}$ into the palate associated with upper left central incisor to first premolar. Overlying mucosa was normal in appearance. Both 22 and 23 are mobile and spacing was found in between them, slight bleeding was present in gingival margin of 22. (Fig: 2)

Panoramic view of radiograph (OPG) revealed a well-defined inverted peer shaped radiolucent lesion (Fig: 3)with displacement of the apex of the teeth $21,22,23,24$. Chairside vitality test was done by hot gutta-purcha stick and found adjacent teeth vital.Provisional diagnosis was made as a globulomaxillary cyst and for surgical procedure informed written consent was taken. Routine hematological test was done to carry surgery and found no abnormality.

At first left lateral incisor was extracted due to severe mobility. Then a ready-made plastic obturator was placed through the socket and cyst lining was sutured with obturator and mucosa.(Fig: 4) Instruction was given to irrigate the cavity by diluted hydrogen peroxide $\left(\mathrm{H}_{2} \mathrm{O}_{2}\right)$ and $1 \%$ Povidonelodine solution after each meal through the opening and periodic weekly examination was done to see any dislodgement, infection and to measure the amount of bone regeneration.
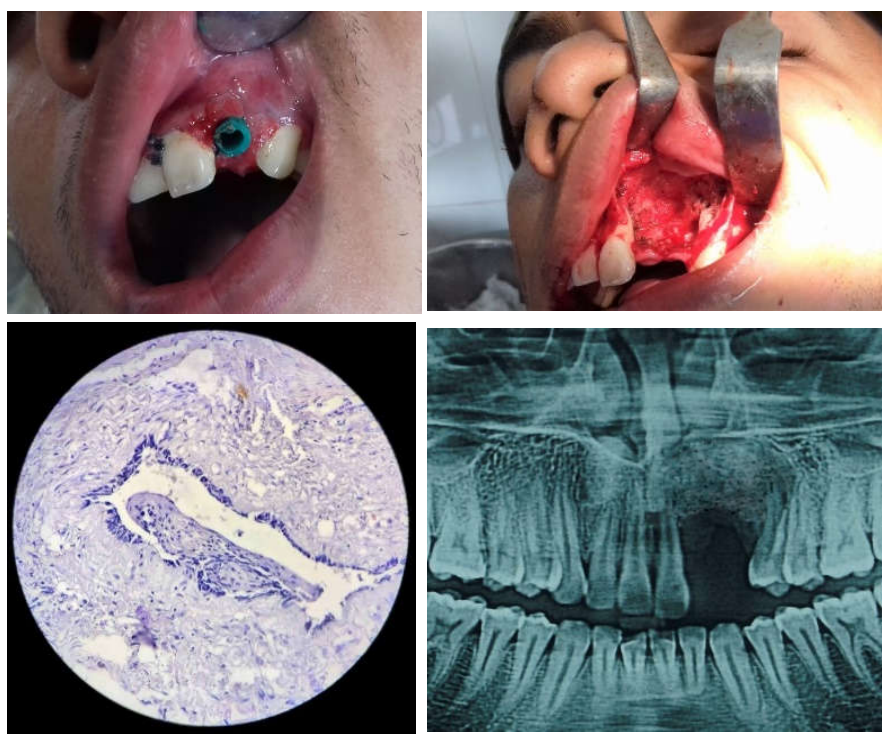

Figure 4: Plastic obturator was placed in the opening. Figure 5: Complete enucleation with cyst lining. Figure 6: Histopathological picture of cyst lining (Hematoxillin and Eosin preparation), Figure 7: OPG after 3 months of surgery showing regeneration of bone (From upper left to right and also lower left to right)

Radiologically, globulomaxillary cyst looks like an inverted pear shaped well-defined radiolucent lesion in between lateral incisor and canine of maxilla. ${ }^{(8)}$ Histopathologically, lining composed of stratified squamous epithelium or pseudostratified ciliated columnar epithelium in globulomaxillary cyst. In our case stratified squamous epithelium found which suggests, it is a developmental cyst of non-odontogenic origin.

Large cyst usually treated by enucleation or in a procedure called marsupialization before enucleation. ${ }^{(9)}$ In our case, marsupialization was done to increase bone regeneration and prevent possible involvement into nasal cavity and damage to adjacent teeth during surgery. After 3 months of enucleation increase radio-opacity is noted in the lesion in panoramic view indicates bone regeneration. (Fig: 7)

Clinical differential diagnoses of globulomaxillary cyst are anterior bony defect, inflammatory odontogenic cyst, adenomatoid odontogenic tumor, and giant cell granuloma. ${ }^{(10)}$ 


\section{CONCLUSION:}

The case reported in this study was successfully treated by marsupialization followed by enucleation. By this, the cavity allows drainage of cystic fluid and regeneration of bone. After follow up, recurrence or any complication was not found. The successful outcome of this case shows that, marsupialization might be a good treatment option for management of globulomaxillary cyst.

\section{ACKNOWLEDGEMENTS:}

We would like to thank Dr. Tasnim Ahmed, MD resident, Dept. of Pathology, BSMMU (Bangabandhu Sheikh Mujib Medical University) for her kind co-operation in providing histopathological image.

\section{CONFLICT OF INTEREST:}

We have no conflict of interest to declare.

\section{REFERENCES:}

1. Steiner D. A lesion of endodontic origin misdiagnosed as a globulomaxillary cyst. Journal of Endodontics. 1999;25(4):277-281. https://doi.org/10.1016/S0099-2399(99)80160-52.

2. Sivapathasundharam B, Rajendran A. Shafer's textbook of oral pathology. 8th ed. Elsevier India Pvt Ltd; 2016.

3. Fathi AL-Omar A, A. Elmorsy K. Treatment of a large maxillary cyst with marsupialization (case report). Oral Health and Care. 2018;3(1). https://doi.org/10.15761/OHC.1000132

4. Dammer U, Driemel O,Mohren W, Giedl C, Reichert T. Globulomaxillary cysts-do they really exist?.Clinical Oral Investigations. 2013;18(1):239246.https://doi.org/10.1007/s00784-013-0954-y PMid:23455575

5. Christ TF. The globulomaxillary cyst: an embryologic misconception. Oral Surg Oral Med Oral Pathol. 1970;30:515-526. https://doi.org/10.1016/0030-4220(70)90169-6

6. Iqbal., S.M., Mishra, K.D. \& Garg, A.K. Globulomaxillary cystnonodontogenic vs odontogenic. Indian J Otolaryngol 40, 68-69 (1988) doi:10.1007/BF02994212

7. D'Silva N, Anderson L. Globulomaxillary cyst revisited. Oral Surgery, Oral Medicine, Oral Pathology. 1993;76(2):182-184. https://doi.org/10.1016/0030-4220(93)90201-E

8. Karjodkar FR. Cysts of Jaws. Textbook of Dental and Maxillofacial Radiology, 2nd ed. New Delhi: Jaypee Brothers Medical Publishers; 2009. p. 522-4.https://doi.org/10.5005/jp/books/10904

9. Saracino $S$, Kleinman M. An unusually large globulomaxillary cyst treated by marsupialization and enucleation. Oral Surgery, Oral Medicine, Oral Pathology. 1968;25(3):298-302. https://doi.org/10.1016/0030-4220(68)90004-2

10. Wysocki GP, Goldblatt LI. The so called "globulomaxillary cyst" is extinct. Oral Surg1993;76:185-6.https://doi.org/10.1016/0030-4220(93)90202-F 